ORIGINAL ARTICLE

AFRICAN JOURNAL OF CLINICAL AND EXPERIMENTAL MICROBIOLOGY

SEPTMBER 2010

ISBN 1595-689X VOL 11(3)

AJCEM/200985/21020

-http://www.ajol.info/journals/ajcem

COPYRIGHT 2010

AFR. J. CLN. EXPER. MICROBIOL 11(3): 159-163

\title{
PREVALENCE AND MANAGEMENT OF FALCIPARIUM MALARIA AMONG INFANTS AND CHILDREN IN OTA, OGUN STATE, SOUTHWESTERN NIGERIA
}

\author{
1* GI Olasehinde, ${ }^{1}$ AA Ajayi, ${ }^{1}$ SO Taiwo, ${ }^{1 B T}$ Adekeye, and ${ }^{2} \mathrm{OA}$ Adeyeba. 1Department of Biological Sciences, \\ Covenant University, Ota, Ogun State, Nigeria; and 2Deptartment of Medical Microbiology and Parasitology, \\ * Correspond: golasehinde@yahoo.com \\ LAUTECH Teaching Hospital, Osogbo, Nigeria
}

\begin{abstract}
Studies were carried out to determine the prevalence of malaria parasite infection among infants and children (0-12yrs) in Ota, Southwestern Nigeria between April and December 2008. The two hospitals used were Ota General Hospital and Covenant University Health Centre, Canaanland, Ota. Thick and thin films were made and stained using standard parasitological procedures. Structured Questionnaires were distributed to ascertain the age, sex, drugs or insecticides used and state of health of the subjects before recruiting them into the study.

Overall, $215(80.5 \%)$ of the 267 children investigated were found to have malaria infection. Age group (0-5 years) had the highest frequency rate of $84.7 \%$ with mean parasite density of 900 and the difference between the age groups was statistically significant $(\mathrm{p}<0.05)$. Children of illiterates from suburb villages had the highest mean parasite density of 850 with $78.1 \%$ prevalence rate. $20 \%$ of the children were given local herbs and $22 \%$ used orthodox medicine as prophylaxis. Only $18 \%$ used insecticide treated mosquito nets while $24 \%$ of the parents spray insecticides to prevent mosquito bites.

There is therefore need for more awareness on effective use of drugs and Insecticide Treated bed nets in malaria hyperendemic regions.
\end{abstract}

Key words: \% Prevalence, malaria parasite, Plasmodium falciparum, infants, Children

\section{INTRODUCTION}

Malaria is the most prevalent tropical disease in the world today. Each year, it causes disease in approximately 650 million people and kills between one and three million, most of them, young children in Sub-Saharan Africa (1). Nigeria is known for high prevalence of malaria and it is a leading cause of morbidity and mortality in the country. Available records show that at least 50 per cent of the population of Nigeria suffers from at least one episode of malaria each year and this accounts for over 45 per cent of all out patient visits (2). Malaria infection during the first five years of life is a major public health problem in tropical and subtropical regions throughout the world (3 and 4).

The disease accounts for 25 per cent of infant mortality and 30 per cent of childhood mortality in Nigeria thereby imposing great burden on the country in terms of pains and trauma suffered by its victims as well as loss in outputs and cost of treatments (5). It has also been documented that children visiting their country of origin import malaria from Nigeria and other hyperendemic countries to the low and non-endemic countries (6). The disease is caused by protozoan parasites of the genus Plasmodium. The most serious forms of the disease are caused by Plasmodium falciparum and Plasmodium vivax (3). The parasite is transmitted by female anopheles mosquitoes (7).

Consequences of severe malaria include coma and death if untreated, young children are especially vulnerable (8). In endemic areas, treatment is often less satisfactory and the overall fatality rate for all cases of malaria can be as high as one in ten (9). For reasons that are poorly understood, but which may be related to high intracranial pressure, children with malaria frequently exhibit abnormal posturing, a sign indicating severe brain damage (8 and 9). Malaria has been found to cause cognitive impairments, especially in children. Malaria causes widespread anemia during a period of rapid brain development and also direct brain damage and this neurologic damage results from cerebral malaria to which children are more vulnerable (10). Over the longer term, developmental 
impairments have been documented in children who have suffered episodes of severe malaria (3). Considering the above complications associated with malaria infection in children, this study therefore was carried out to assess the prevalence of malaria parasite infection among children between zero and twelve years of age in relation to attitudes and social pattern of living as factors affecting their exposure to malaria parasite infection.

\section{MATERIALS AND METHODS}

Two hundred and sixty seven infants and children between the ages of 0 and 12 years that were referred to the laboratory for malaria diagnosis test at the General Hospital, Ota and Covenant University health centre, Canaanland Ota, Ogun State, South West Nigeria between April and December, 2008 were recruited for this study.

\section{Study Site}

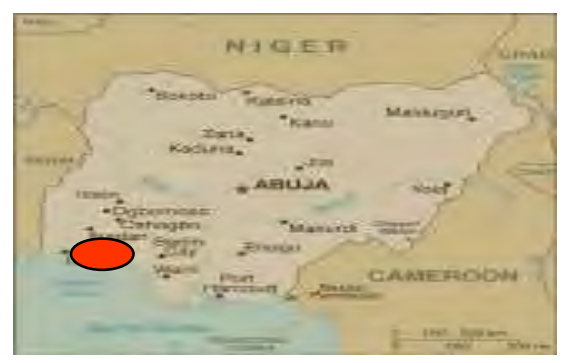

$\bigcirc$ Ota, Ogun State, Nigeria

Safety procedures were adopted in the collection of finger-prick blood samples by swabbing the area to be sampled with $70 \%$ alcohol and allowed to dry before collection. Experienced medical laboratory scientists did sample collection in the hospitals. Thick and thin blood films were made on clean slides and labeled accordingly as recommended by the World Health Organization (WHO) (11).

The thin films were fixed with methanol and all films were stained with $3 \%$ Giemsa stain at $\mathrm{pH}$ 7.0 for $30 \mathrm{~min}$ as recommended by WHO (12). Blood films were examined microscopically using 100X (Oil immersion) objectives as described by Cheesbrough (11). The thick films were used to determine the parasite densities while thin films were used to identify the parasite species and infective stages. Parasite density per microlitre of blood was estimated from the thick film, taking the number of leucocytes per microliter of blood as 8,000 and was expressed as:

Parasite count $\times 8,000$

Parasite density $=$ No of $\mathrm{WBC}$ counted

Questionnaires were designed and administered to parents of infants and older children determine the age, sex, drug usage for prophylaxis, attitude to use of Insecticide treated mosquito nets. The statistical analysis for significance was done using chi-square test.

Scientific and Ethical permit/clearance was obtained from the Nigerian Institute of Medical Research - Institutional Review Board (NIMRIRB) and Covenant University Ethics Committee before this research work was carried out. The Ogun State Ministry of health (Hospitals Management Board) was also informed before this research was carried out. Consent for the children was provided by the parents/guardians while some of the participants provided the assents by nodding.

\section{RESULTS}

The prevalence of malarial parasite in infants and children according to age is shown in Table 1. Of the 267 samples examined, 215had malaria parasite in their blood $(\mathrm{p}<0.05)$. The distribution of malaria parasite according to the methods used for prevention of mosquito bite by the patients (Table. 2) revealed that those who did not use any method to prevent the bite of mosquitoes have the highest prevalence rate of $(90.9 \%)$ and mean parasite density of 900 .

Table 1: Prevalence of Malaria Parasite in children according to age

\begin{tabular}{|l|l|l|l|}
\hline $\begin{array}{l}\text { Age } \\
\text { group } \\
\text { (yrs) }\end{array}$ & $\begin{array}{l}\text { No. } \\
\text { Examined }\end{array}$ & $\begin{array}{l}\text { No } \\
\text { Infected } \\
(\%)\end{array}$ & $\begin{array}{l}\text { Mean } \\
\text { Parasite } \\
\text { Density } \\
\text { (MPD) }\end{array}$ \\
\hline $0-5$ & 177 & $150(84.7)$ & 900 \\
\hline $6-12$ & 90 & $65(72.2)$ & 600 \\
\hline Total & 267 & $215(80.5)$ & 750 \\
\hline
\end{tabular}


Table 2: Distribution of Malaria Parasite according to mosquito prevention Method

\begin{tabular}{|c|c|c|c|}
\hline $\begin{array}{l}\text { Preventive } \\
\text { Methods } \\
\text { used }\end{array}$ & $\begin{array}{l}\text { Total } \\
\text { No. of } \\
\text { infants } \\
\text { and } \\
\text { children } \\
(\%)\end{array}$ & $\begin{array}{l}\text { No } \\
\text { Infected } \\
\text { out of } \\
\text { patients } \\
\text { using } \\
\text { method } \\
(\%)\end{array}$ & $\begin{array}{l}\text { Mean } \\
\text { Parasite } \\
\text { Density } \\
\text { (MPD) }\end{array}$ \\
\hline $\begin{array}{ll}\begin{array}{l}\text { Bed } \\
\text { (ITN) }\end{array} & \text { nets } \\
\end{array}$ & $48(18)$ & 23(47.9) & 580 \\
\hline Insecticides & $64(24)$ & $45(70.3)$ & 750 \\
\hline $\begin{array}{l}\text { Mosquito } \\
\text { repellent } \\
\text { cream }\end{array}$ & $20(7.5)$ & $16(80.3)$ & 910 \\
\hline $\begin{array}{l}\text { Window/door } \\
\text { nets }\end{array}$ & $\begin{array}{l}113 \\
(42.3) \\
\end{array}$ & 111(89.5) & 870 \\
\hline None & $22(8.2)$ & $20(90.9)$ & 900 \\
\hline Total & $267(100)$ & $215(80.5)$ & 750 \\
\hline
\end{tabular}

The prevalence rate of malaria and mean parasite density (580) was significantly low (47.9\%) among the children who used Insecticide treated bed nets. Prevalence of malaria parasite in children based on drug used as prophylaxis is shown in Table 3 . There is a significantly low prevalence $(55.2 \%)$ among those who used antimalarial drugs as prophylaxis when compared with patients who did not use any drug as prophylaxis (92.5\%). Those who took local herbs (indigenous drug) had prevalence rate of $64.8 \%$.

Table 3: Prevalence of Malaria Parasite in relation to prophylactic Antimalarial drugs used by study population

\begin{tabular}{|l|l|l|l|}
\hline Drug used & $\begin{array}{l}\text { Total } \\
\text { No. of } \\
\text { those } \\
\text { using } \\
\text { drug } \\
(\%)\end{array}$ & $\begin{array}{l}\text { No. } \\
\text { Infected } \\
(\%)\end{array}$ & $\begin{array}{l}\text { Mean } \\
\text { Parasite } \\
\text { Density }\end{array}$ \\
\hline Quinolines & $21(7.8)$ & $18(85.5)$ & 890 \\
\hline Sulfonamides & $17(6.4)$ & $9(52.9)$ & 800 \\
\hline $\begin{array}{l}\text { Artemisinin } \\
\text { Combination } \\
\text { Therapies }\end{array}$ & $16(6.0)$ & $5(40.1)$ & 760 \\
\hline Local herbs & $53(19.9)$ & $35(64.8)$ & 800 \\
\hline No drugs & $160(59.9)$ & $148(92.5)$ & 990 \\
\hline Total & $267(100)$ & $215(80.52)$ & 750 \\
\hline
\end{tabular}

Table 4: Prevalence of Malaria Parasite According to Place of Residence

\begin{tabular}{|l|l|l|l|}
\hline $\begin{array}{l}\text { Place of } \\
\text { residence }\end{array}$ & $\begin{array}{l}\text { Number } \\
\text { Examine } \\
\mathrm{d}\end{array}$ & $\begin{array}{l}\text { Number } \\
\text { Infected } \\
(\%)\end{array}$ & $\begin{array}{l}\text { Mean } \\
\text { Parasit } \\
\text { e } \\
\text { Densit } \\
\text { y }\end{array}$ \\
\hline $\begin{array}{l}\text { Boarding } \\
\text { House }\end{array}$ & 52 & $47(90.4)$ & 870 \\
\hline $\begin{array}{l}\text { Campus } \\
\text { Quarters }\end{array}$ & 81 & $60(74.1)$ & 750 \\
\hline Housing Estate & 23 & $12(52.2)$ & 760 \\
\hline $\begin{array}{l}\text { Town/city } \\
\text { setting }\end{array}$ & 80 & $71(88.8)$ & 800 \\
\hline $\begin{array}{l}\text { Village/Remot } \\
\text { e setting }\end{array}$ & 32 & $25(78.1)$ & 850 \\
\hline Total & 267 & $215(80.5$ & 750 \\
\hline
\end{tabular}

The distribution of malaria parasite according to residential environment of the parents and children where the highest prevalence of $90.4 \%$ and parasite density of 870 was found among a set of students from a boarding school in the suburb of Ota (Table 4).

\section{DISCUSSION AND CONCLUSION}

Malaria remains one of the world's greatest childhood killers and is a substantial obstacle to social and economic development in the tropics. Plasmodium falciparum infection is the major cause of morbidity and mortality especially among the vulnerable groups to which children, especially aged less than 5 years belong (8).

In this study the prevalence of falciparum malaria in children between 0 and 12 years is $80.5 \%$ with mean parasite density of 750 . This is in agreement with the findings of other workers in malaria endemic countries (13 and 14). The high prevalence could be due to the fact that this study was conducted just before the onset of rains till the end of raining season. This period has been marked as a period of high transmission (15).

Prevalence rate of $84.7 \%$ was recorded among children between zero and five years. It was observed that newborns and infants between age 5 days and three months who presented with fever were found to be positive for falciparum malaria. Similar observations have been reported in endemic and hyperendemic areas (14 and 16), where it was found that the parasite rate increases with age from $0-10 \%$ in the first three months of life to 80 to $90 \%$ by one year of age and the rate persists at a high level during early childhood. The presence of malaria parasites in 
the blood of newborns may be as a result of congenital malaria as reported by Sotimehin et al. (14). Congenital malaria, defined as the presence of malaria parasites in the erythrocytes of newborns aged $<7$ days, was considered rare in endemic areas until recent studies started reporting high prevalence rates (14). The high prevalence rate in the study area could result to childhood anaemia and other severe conditions such as cerebral malaria as reported by other workers (3 and 9).

Following the demonstration that vector control measures can substantially reduce malaria transmission, malaria morbidity and all-cause child mortality, it has been suggested that insecticide-treated materials (ITMs) may also curb the spread of antimalarial drug resistance (17). There is a significantly low prevalence rate of malaria $(47.9 \%)$ among the children that used Insecticide Treated Nets, although only $18 \%$ of the sample population used Insecticide Treated Nets (ITNs). Majority of households do not prevent mosquito bites and disease transmission in any way and a high prevalence rate of $90.9 \%$ and mean parasite density of 900 was recorded among this group of children. There is therefore the need to intensify awareness and education and to make the ITNs available at affordable prices in these malaria hyper endemic areas as the use of insecticide-treated nets decreased the number of malaria cases in children. Boarding house students should be encouraged to use bed nets so as to reduce transfer of infection among the students as the highest prevalence rate of $90.4 \%$ was found among students who live in the same hostel in a boarding house system.

It is also essential to avoid stagnant pools and poor environmental conditions, which encourage the breeding of mosquitoes. This is demonstrable as the prevalence rate among the children whose parents live in clean and hygienic environment like campuses and well laid out housing estates was low i.e. prevalence rates of 52.2 and 74.1 in housing estates and University campus respectively.

It has been observed in this study that antimalarial drugs are used as prophylaxis without doctors' prescription. Even artemisinin Combination Therapies (ACTs) have been used. Self-medication is a practice that is very common among people living in malaria endemic areas (18). This study shows that the number of children who had taken antimalarial drugs as prophylaxis was considerably high. This could be as a result of awareness created through education on home management and control of malaria among the pregnant women and mothers. Parents should therefore be educated on the safe effective use of antimalarial prophylactic drugs as too much exposure to antimalarial drugs could lead to the development of drug resistance. It was also observed from this study that there was low prevalence rate (64.8\%) among the children that were given local herbs. However the community and the producers of these indigenous herbs need to be educated on strict adherence to environmental hygiene. There is also urgent need to encourage and empower researchers to identify the active ingredients in the effective local herbs for mass production. These may eventually lead to drug discovery in the bid to eliminate malaria.

\section{Acknowledgements}

We wish to acknowledge the management of Covenant University for funding this research. We also acknowledge the members of staff, Medical diagnostic laboratory of Covenant University health Centre and General hospitals, Ota and Abeokuta for their assistance in the collection of samples.

\section{REFERENCES}

1. Hay S, Guerra C, Tatem A, Noor A and Snow R (2004). “The global distribution and population at risk of malaria: past, present and future." Lancet 4(6):327-236.

2. Ojurongbe O, Ogungbamigbe TO, FagbenroBeyioku AF, Fendel R, Kremsner PG, Kun JF 2007. Rapid detection of Pfcrt and Pfmdr1 mutations in Plasmodium falciparum isolates by FRET and in vivo response to chloroquine among children from Osogbo, Nigeria. Malar J 6: 41.

3. Trampuz A, Jereb M, Muzlovic I, Prabhu R (2003). "Clinical review: Severe malaria." Crit Care 7 (4): 315-23.

4. Greenwood BM, Bojang K, Whitty CJ, Targett GA (2005). "Malaria". Lancet 365: 1487-1498.

5. Ogungbamigbe $\mathrm{T}$, Ogunro $\mathrm{P}$, Elemile $\mathrm{P}$, Egbewale B, Olowu O, Abiodun O 2005. Presciption patterns of antimalarial drugs among medical practitioners in Osogbo Metropolis, South-West Nigeria. Trop Med Health 33: 201-208.

6. Katrin S., Fabrice L., Gérard K., Nicola L., David B., Meghna D., Simone G., Stefania D., Yasutaka M., Ragnhild J., Eskild P., John K., 
Robert S., and Patricia S. (2009). Imported Malaria in Children in Industrialized Countries, 1992-2002. Emerg. Infect. Dis. 15 (2):185

7. Adefioye, O.A., Adeyeba, O.A., Hassan W.O. and Oyeniran, O.A. (2007). Prevalence of Malaria Parasite Infection among Pregnant Women in Osogbo, Southwest, Nigeria. American-Eurasian Journal of Scientific Research 2 (1): 43-45.

8. Idro, R, Otieno G, White S, Kahindi A, Fegan G, Ogutu B, Mithwani S, Maitland K, Neville BG, Newton CR. (2007). "Decorticate, decerebrate and opisthotonic posturing and seizures in Kenyan children with cerebral malaria". Malaria Journal 4 (57). Online biomed Central.

9. Mockenhaupt F, Ehrhardt S, Burkhardt J, Bosomtwe S, Laryea S,

Anemana S, Otchwemah R, Cramer J, Dietz E, Gellert S, Bienzle U

(2004). "Manifestation and outcome of severe malaria in children in

northern Ghana." Am J Trop Med Hyg 71 (2): 167-72.

10. Boivin, M.J.(2002). "Effects of early cerebral malaria on cognitive ability in Senegalese children," Journal of Developmental and Behavioral Pediatrics 23 (5): 353-64.

11. Cheesbrough M (2000). District laboratory practice manual in Tropical Countries pt 2. Cambridge University press.

12. WHO. (2000). Malaria diagnosis, New Perspectives. Geneva, World Health Organisation.WHO/CDS/RBM/2000.14, WHO/MAL/2000.1091.
13. Aribodor U.D.N., Njoku O.O., Eneanya C.I. and Onyali I.O. (2003). Studies on prevalence of malaria and management Practices of the Azia community, Ihiala LGA, Anambra State, South East Nigeria. Nigerian Journal of Parasitology 24:33-38.

14. Sotimehin, S.A., Runsewe-Abiodun T.A., Oladapo, O.T. Njokanma O.F. and Olanrewaju D.M. (2008). Possible Risk Factors for Congenital Malaria at a Tertiary Care Hospital in Sagamu, Ogun State, Southwest Nigeria. Journal of Tropical Pediatrics,

http://tropej.oxfordjournals.org/misc/term s.shtml

15. Ukoli FMA (1990) Introduction to Parasitology in Tropical Africa. Chichester, Wiley \& Sons, 1990, pp 399-429.

16. Kakkilaya B.S (2006). www.malariasite.com.

17. Diadier A.D., Colin S., Issa N, Amadou T.K., Rosalynn O., Hirva P., Cally R., Edith I, Brian, M.G. and Simon N.C. (2007). Curtains are not associated with greater circulation of drug-resistant malaria parasites, or with higher risk of treatment failure among children with uncomplicated malaria in Burkina Faso. Am. J. Trop. Med. Hyg., 76(2): 237-244.

18. Akanbi O.M, Odaibo A.B., Afolabi K.A. and Ademowo, O.G. (2005). Effect of SelfMedication with Antimalarial Drugs on Malaria Infection in Pregnant Women in Southwestern Nigeria. Med Princ Pract 2005; 14:6-9. 